\title{
Malignant fungating wounds - the meaning of living in an unbounded body
}

Sebastian Probst, Zurich University of Applied Sciences

Anne Arber, University of Surrey

Sarah Faithful, University of Surrey

\begin{abstract}
Background: Malignant fungating wounds may have a significant physiological, psychological and emotional consequences on patients and their families. This study focuses on understanding the lived experiences of patients with a malignant fungating breast wound and their informal carers.
\end{abstract}

Method: The methodological framework of interpretative phenomenological approach according to Heidegger was used. Nine patients were interviewed from January until November 2009.

Results: The results demonstrate that most of the patients and their informal carers were on their own while struggling with the erosion of their physical boundaries. The women report a lack of information and advice about how to manage the wound as well as the physical and social limitations imposed on them because of copious wound exudate, odour and bleeding. The women used many different methods and approaches to maintain the boundedness of the body.

Conclusion: This study contributes to understanding that losing control over the body meant for the women losing control over themselves and their lives. The unboundedness was demonstrated through the symptom experiences. Therefore the care of women needs strategies that are integrated in a palliative, holistic, empathic approach. In particular skills for palliative wound care among medical and nursing staff need to be developed as the women and their carers report a lack of information and advice about how to manage the wound as well as the physical limitations and psychosocial consequences of struggling to maintain the boundedness of the body. 


\section{Background and context}

Current evidence at a European level (Eurocare 4, 2010) shows considerable improvement in survival following treatment for cancer. However for some, cancer is still an aggressive and chronic disease (Singletary and Cristofanilli, 2008) resulting in unpleasant symptoms, psychological distress and sometimes malignant fungating wounds. In 2006 in Europe, there were an estimated $3,191,600$ cases of cancer diagnosed and 1,703,000 deaths from cancer. Women with breast cancer make up a sizeable proportion of people with cancer with 429,900 cases, which, accounts for $13.5 \%$ of all cancers, making breast cancer the most common cancer in Europe (Ferlay, et al., 2007). Improvements in screening and treatment have reduced breast cancer mortality in Europe by 19\% between 1989 and 2006 (Autier, et al., 2010). In Switzerland the incidence in breast cancer is similar to that of Europe with 26,222 new cases diagnosed between 2003 and 2007, resulting in an average of 5,244 cases per year which represents $32 \%$ of all cancer cases (Swiss-Association-of-Cancer-Registries, 2011). Breast cancer occurs in women who are in good health and mostly in those without any previous illness. After the diagnosis they are confronted with a life threatening illness, that changes their life and that of their families quickly and fundamentally (Schmid-Buchi, et al., 2005). Those with advanced cancer can now live for long periods; with a good quality of life due to supportive care and symptom management into the end-of-life period. It is important that cancer services and palliative care are integrated to enable good symptom support and this requires national guidelines and accredited standards (Thompson et al 2010). However there are a shortage of health professionals educated to use a palliative care approach in the context of the complex symptoms associated with a malignant fungating wound (Lo, et al.,2008). 


\section{What is a malignant fungating wound}

A malignant fungating wound is an infiltration of a cancer or metastasis into the skin and the afferent blood and lymph vessels in the breast (Grocott and Cowley, 2001; Young, 2005). Unless the malignant cells are brought under control, through treatment with chemotherapy, radiotherapy or hormone-therapy, the fungation may spread outwards by local extension and as a consequence it causes damage through a combination of loss of vascularity, proliferative growth and ulceration (Grocott, 2000; Mortimer, 2003). Women still present at initial diagnosis with a malignant fungating wound. They may delay seeking help and try to hide the reality of the cancer, which highlights the huge impact and shame associated with such a wound on an intimate part of the body, which is deeply significant for sexuality and feminitiy (Boon, et al., 2000). Those with malignant fungating wounds experience may problems such as excessive exudate and leakage, unpleasant odour from the wound, and the fear of being diagnosed with cancer, which may lead to delay in seeing medical help (Lund-Nielsen, et al., 2011).

It is difficult to determine accurately the numbers of patients being treated for malignant fungating wounds as there are no exact statistics of the incidence of these wounds across Europe. Incidence rates are not recorded in population-based cancer registers (Grocott and Cowley, 2001). Most data are based on estimates made within a given population (Ivetic and Lyne, 1990). A survey of the prevalence of fungating wounds undertaken by Thomas (1992) in the UK is often cited in the literature. He used information collected retrospectively from radiotherapy and oncology units, and reports a projected annual figure of 2417 malignant wounds. This gives a monthly total of 295 patients presenting with metastatic skin involvement. The prevalence of fungating wounds in Thomas' study ranges from 5 to $10 \%$ with $5 \%$ referring to a primary tumour and $10 \%$ to metastasis (Thomas, 1992).

The most frequent location of the fungating wound was the breast $(62 \%)$, followed by the head and face (24\%), the genitals, groin and the back (3\%) and other areas (8\%) (Thomas, 1992). A survey in Switzerland, reported a prevalence of $6.6 \%$ (Probst, et al., 2009). Findings 
in the latter study concerning location, were similar to that of Thomas (1992) in which the most frequent location of the wound was, the breast (49.3\%) followed by the neck $(20.9 \%)$, chest $(17.6 \%)$, extremities (16.6\%), genitalia (16.6\%), head (13.5\%) and other $(1.7 \%)$. It can be predicted that about five per cent of patients with cancer will develop a malignant fungating wound. The life expectancy for a person living with such a wound is very short with an average of six to twelve months survival (Lo, et al., 2008). It is evident from a number of studies that malignant fungating wounds cause immense distress and significant morbidity and they are a neglected aspect of cancer nursing practice in some settings (Lo, et al., 2008; 2011; Wilkes, et al., 2003).

\section{$\underline{\text { Review of the literature }}$}

One of the biggest problems identified in clinical reviews on malignant fungating wounds is symptom management. It is stated that this is as challenging area for patients, informal carers as well as for health care professionals (Grocott, 2007; Lo, et al., 2008; Probst, et al., 2009). The most common symptoms of malignant fungating wounds are that of malodour, excessive exudate, pain, bleeding and itching (Grocott, 2007; Probst, 2010). Maida et al. (2009) conducted a prospective sequential case series $(n=67)$ of palliative medicine consultations with the aim of quantifying the prevalence of malignant fungating wounds and wound symptoms at the point of referral. Further they were looking at the relationship between wounds, age, gender, the Palliative Performance Scale, and the anatomic site. $67.7 \%$ of the patients experienced one or more wound related symptoms. Pain was the most common symptom reported (31.2\%), followed by exudate (14.6\%), odour (10.4\%), itching $(5.2 \%)$, bleeding $(4.2 \%)$ and other symptoms like crusting. It was noted that $28.4 \%$ of the wounds were symptom free (Maida, et al., 2009).

A study of 14 nurses, four patients and one carer, conducted in Australia, report that malignant fungating wounds are an intense and unforgettable experience with most of the 
distress caused by malodour (Alexander, 2010). Another UK study provides insight in to the meaning of living with a malignant fungating wound from the perspective of 5 women. The women who felt that there was an overwhelming sense of vulnerability in living within a body that was continually changing and could not be trusted (Piggin and Jones, 2007). Furthermore the visibility of the cancer wound caused immense distress, represented a huge new challenge and changed relationships with family and friends.

The impact of a malignant fungating wound upon day-to-day life and psychological health is illustrated in Lo et al.'s research. Lo et al. (2008) provides a grounded theory study of the lived experiences of 10 patients (six women and four men) with malignant fungating wounds in Taiwan. The researchers provide a detailed description of the trajectory that patients experience from the first stages of wound development through to the end stage of their illness (Lo, et al., 2008). Five themes emerged from the data which were: 'declining physical wellbeing', 'wound related stigma', 'need for expert help', 'strategies in wound management' and 'living positively with the wound'. The findings demonstrate how patients experienced distress related to the wound-related symptoms as well as embarrassment due to symptoms like malodour and leakage of exudate. The wound symptoms affected participants' social behaviour and interaction and resulted in a degree of social isolation. Lo et al. (2008) describe the benefits described by those patients who were seen by a wound care specialist, which enabled them to live more positively with the wound in terms of coping with dressing changes, access to modern dressings and reduction in the distressing experience of odour and pain. Care from the wound care specialist enabled patients to be more comfortable, less distressed and reduced the experience of stigma and social isolation because the wound related symptoms were managed. Low levels of information and practical help from health professionals led some patients to use management strategies that could harm their wound and exacerbate problems such as bleeding (Lo et al., 2008). Only $15 \%$ of patients with a fungating wound, in one multi-centre study, $(n=70)$ are reported to have a specialist nurse involved in the care of their wound (Lo, et al., 2011). 
Malignant wounds do not heal and are generally managed with palliative methods to control both wound related symptoms and to manage pain, which is one of the most common symptoms identified by patients and by caregivers (Maida et al., 2009; Schulz et al., 2002). In relation to uncontrolled symptoms and wounds that leaked Lawton (1998) observed how patients who experienced the break down in the surface of their bodies from wounds and other problems, exhibited a loss of self and social identity when their bodies became irreversibly unbounded. Although palliative care seeks to palliate the unbounded body and where possible enable the bounding of the wound there is evidence from a number of studies that this group of patients with malignant wounds receive inadequate specialised professional help in relation to palliation of the fungating wound (Lo et al. 2008; Probst 2010)

The aim of the research reported in this article is to explore the experiences of women with a malignant fungating breast wound living in the community in Switzerland.

\section{Methodology and method}

The perspective taken in this study is that of interpretative phenomenological analysis (IPA). IPA is a qualitative approach influenced by the hermeneutic version of phenomenology. IPA is designed to explore how human beings make sense of a major life experience in its own terms (Smith, et al,, 2009). Various inductive methods have been developed by supporters of hermeneutic phenomenological research. Although there is no single method, a common basis around the exploration of the phenomenon and the essence of experience unifies and the different methods. Hermeneutic phenomenology following Heidegger and adapted by van Manen (1990) is the approach taken in this study.

Participants

A purposive sample of nine participants were recruited from three Cantons of Switzerland (Zurich, Bern and Baselland) between January and November 2009. Initial contact was made in each Canton through a nurse or physician. The inclusion criteria were the following: Participants who were living with a malignant fungating breast wound, which was present for at least six months; aged between 40 and 80 years, able to understand German orally and in 
written form; and able to give written informed consent and willing to participate in a interview lasting up to one hour.

Nine patients were recruited over a period of eleven months. Semi structured interviews were conducted lasting between 55 and 95 minutes. The location of the interviews was chosen to suit participants and were mostly conducted by one researcher (SP) in the participants home. The interviews took a semi-structured approach to explore the participants inner experiences and meanings related to living with a malignant wound. The questions were open-ended making use of probes for example: "Can you tell me more about a particular day?". A topic guide was used to guide the development of the questions..

Data analysis

Interpretative phenomenological analysis does not prescribe any one method of data analysis. Analysis of the interviews involves four steps, as described by van Manen (1990): A verbatim transcription of the interview is made. This was done by the researcher. In doing so, the whole interview was transcribed from Swiss German into Standard German. Only key statements were translated into English. Each transcript was read and re-read in an attempt to become immersed in the text and familiar with what was being said about the lived experience of the wound. After reading and rereading the transcript a number of times, certain categories and phenomena were marked and eventually these were clustered together under themes. The final step in analysis involved analysing how each of the phenomena identified will be categorised. This process enabled the researcher to identify and discover the essential qualities of the narrated experiences and the phenomenon of the unbounded body emerged. To organise and format the data, the qualitative computer analysis program MAXqda2 $\AA$ was used. Ethical approval was granted by the ethical committee of each Canton and the University of Surrey, Guildford, UK.

\section{Findings}


All the women described how living with a malignant fungating wound was challenging and traumatic. Seven women already had a diagnosis of breast cancer and had lived with it for many years before developing the malignant wound. Many of the women had been treated by mastectomy or breast-preserving surgery, while others also received adjuvant treatments (e.g. chemotherapy, radiotherapy, hormones). Following treatment, they had lived for years without any problems until their breast ulcerated and the cancer invaded the skin of their breast. However, Christine and Lisa were only diagnosed when the tumour in their breast broke through the skin. They did not pay attention to the ulceration on their skin, thinking they had hurt themselves, so blocked it out of their mind and delayed seeking medical help.

Initially all women tried to manage their wound by themselves. At this stage they were confronted with wound-related symptoms like exudate, wound odour, wound pain and bleeding. These symptoms aroused revulsion and had a significant impact on their mental well-being. They were embarrassed by such symptoms, which had consequences for their social life. To minimise embarrassment, they tried to manage the wounds themselves. Two categories emerged from the data: the first category "Having to simply deal with the situation" and the second category "Having this problem is very embarrassing". Women reported that living with a malignant fungating wound gave rise to new challenges in their life and changed their life completely. The wound was a visible sign of advanced disease. Different kinds of strategies were tried in order to deal with the situation, which are discussed next.

\section{Having to simply deal with the situation}

This category of "Having to simply deal with the situation" identifies the strategies the women deployed to hide and disguise the visibility of their cancer. The women said that, due to the treatment of the disease and/or prevention of wound-related symptoms, they had to adjust their daily life as the cancer and the wound progressed. The breakthrough of the cancer on the surface of the breast was the point at which the cancer became visible. At this point they 
had to cope with a multitude of problems such as wound odour, bleeding, wound pain, leakage of exudate, and itching. They all managed the situation as best as they could by themselves. It was difficult for the women to dress their wounds because of the uncontrollable and unpredictable symptoms particularly exudate that could appear at any time during the day or night.

The above category is subdivided into four subcategories: "Odour coming from the breast to the nose", "Festering like a running nose", "Never knowing if it bleeds or not", and "Bursting because of the terrible pain".

\section{Odour coming from the breast to the nose}

Wound odour was a significant symptom that eight of the women reported as an issue that caused them distress. The problem of odour is identified in most research as one of the main problems with this type of wound and it causes most distress to women, as well as informal carers and health care professionals (Grocott, 2007; Probst, et al., 2009). Wound odour is one of the most difficult symptoms to treat as malignant fungating wounds are polymicrobial, containing a wide spectrum of aerobic and anaerobic bacteria that contribute to the odour coming from the breast (Bowler, Jones, Davies, Coyle, 1999). Malodour is a subjective issue that depends on many variables such as the patient's ability to perceive odour. Helen explains how she felt and how she dealt with the situation of wound odour:

\footnotetext{
"Yes it came from your breast directly to your nose, well you smelt it yourself. That is awful. You cannot describe this smell. It is awful. Well it's as if somebody was mouldy. And I had a feeling that other people smelt it too. So I started to stuff towels and things in it to close it, so that the smell does not appear straightaway. But, dealing with it that way worked for a bit."
}

Although Helen like most of the women tried everything she could to hide the odour this only 'worked for a bit'. The problem with this symptom is that it is difficult to hide because the management possibilities are limited to three main elements: systemic metronidazole, topical 
metronidazole and/or antimicrobials and charcoal dressings (Grocott, 2000). Helen explains how she, as the affected party, smelt the wound first, but most of the time she felt that people in her environment could smell it too. To hide the malodour was a major task. The women repeatedly packed any materials they could get hold of around their breast to catch the discharge and to prevent the smell permeating. This constant anxiety limited their daily activities and caused distress.

Some participants (Helen, Berta and Lisa) said they thought that their body was putrescent like rotten meat and Helen described the smell as 'mouldy' and used all kind of materials to seal the wound. She explains.

"In the beginning I was told about the smell by several people. That was very stressful for me especially when someone told me I stank. So I washed it several times a day with cold water. This odour was really terrible. You might compare it with the smell of a piece of rotting meat. So I sealed it with gauze and put essential oils on it. Apart from that I used lots of perfume."

Helen describes the stressful situation of living in a body that feels like it is not only mouldy but rotting. The comparison with the smell and rotting meat is unpleasant and the smell escapes unobstructed. However Helen is trying to use her own strategies in a skilled and creative way to contain the smell using perfume, gauze and essential oils to try to control and disguise the odour. Helen like other participants had to come up with that strategy by herself as she felt no one else could help her with the wound. Moreover, the malodour and the intensive labour of cleaning and dressing the wound took an immense amount of time and was one of the factors that contributed to some women choosing to isolate themselves in the home.

\section{Festering like a running nose}

Festering due to excessive exudate caused many problems for the women. Helen expressed her experiences of feeling stressed due to the large amount of exudate: 
"It was festering like a running nose. I had to wash my clothes all the time. Well I changed four to six times a day. That was so labour intensive. Well, so I decided to expose my breast to the air and waited until it dried up a bit."

The consequences of losing the physical boundaries of the skin on the breast allowed uncontrolled exudate and because the dressings could not contain the exudate frequent changes of clothes was required, increasing the amount of time in washing clothes and in Helen's case taking time to expose the wound to the air to dry. All these strategies took time and could lead to women staying in the home where they felt safe from scrutiny and negative comments that damaged their identity.

Lisa reported how embarrassed she felt about wound leakage, and how frustrated she felt about having to redo time consuming dressings to contain the exudate:

"And this leakage, I hate it. Every time I woke up my nightdress was wet. This shocked me every time. And this wasn't the only time of day it was a problem. I had to redo my dressing nearly every four hours because it was leaking. It was so stressful. It took so much time and a lot of material. And when you dressed it you do not know if what you did was right or wrong. Before going out I had to think about so many things, like how long would this dressing last. It was so time consuming."

Lisa describes her emotional reaction to the wound in that she has a 'hate' for it and found it shocking. She was also uncertain about whether the dressing is applied correctly, due to the constant leaking, and like Helen found it very time consuming and it really constrained her ability to move out of the home as she had to renew it every four hours.

\section{Never knowing if it bleeds or not}

A number of participants described how bleeding affected their life. Anna was self-employed and had gone back to work because she had her own business and was afraid of losing her clients. On one occasion, in a work meeting, the wound began to bleed and blood was 
seeping into her clothing. To manage this situation she always had spare clothes in her office so she could change and continue with her work:

"Yes, once I was sitting in the office with a client, yes, and I was lucky that I was wearing a jacket, because my bra and my blouse were again full of blood. Yes that was very unpleasant. So I had to go and change."

Anna felt lucky to be wearing a jacket, which disguised the bleeding and gave her time to change her clothes. Berta also talked about the stress of controlling the oozing body fluids. Body fluids are normally contained within the person's body. This situation is stigmatising for the women as there is an expectation in society that body fluids are controlled and the body boundary is intact. For the women they were struggling as best they could to have these problems under control. However they were successful only up to a point where their body let them down and caused immense emotional and social distress.

Certain activities, such as the weekly pattern of going to the sauna, could not be undertaken because of physical symptoms like bleeding:

"Yes, because of the wound I could no longer go to the sauna. I used to go to the sauna every week. Yes, yes occasionally it was bleeding very strongly."

This statement illustrates how constricting it is to live in an unbounded body. In Switzerland, going to the sauna is a very common activity especially during wintertime. Because of the unboundedness of their body the women had to dispense with many of the activities of their daily life like Anna who could not go to the sauna anymore. Patients suffer, as a consequence of their disease, from embarrassment and shame leading to a spoiled identity that an unpredictable wound can bring to their social life and social interaction (Moffat, 2001).

\section{Bursting because of the terrible pain}

In addition to management of malodour and bleeding, the women reported wound-related pain as having a serious impact on their quality of life. Physical pain caused by malignant fungating wounds is a complex phenomenon. This pain can be caused through the growing 
tumour, the pressure of the tumour on other body structures, swelling resulting from impaired capillary and lymphatic drainage, wound infection, exposure of dermal nerve endings or due to the change of the dressings (Probst, 2010). Going to a physician to get some painkillers was problematic as it meant that they have to show their wound to the physician and this was embarrassing for them. Most of the women did not want this so they bought over-the-counter pain medication. Others who went to a physician received a prescription for pain medication. The women were sometimes afraid to take a lot of pain killers and this is why the prescribed medication was either taken irregularly or the prescription was never converted.

Berta used the metaphor of a knife of 'stabbing' to characterise her wound pain. Such characterisation revealed a basic feature of patient's experiences and in Berta's experience the pain was very acute and sharp:

"I suffered so much from it. It was like somebody was stabbing your breast with a stick."

Different methods were used to manage pain:

"Oh and when there was that pain I placed my hands on my breasts. Don't ask me what it was but the pain went away. But when the pain became severe, somehow I lost my own healing power (which we all have). I lost it. This totally ate me up."

This statement by Berta illustrates the diversity of methods used by women to treat the wound and the pain. Berta and Livia believed the wound was an act of nature, beyond control. The method of placing hands on the breast gave the power to relieve the pain and bring the pain under control. Bertha sees this as her own healing power. Many people have an intuitive sense that, for example, talking to themselves can be healing and in Berta's case enclosing her hands over the breast supported the breast and eventually the pain diminished. However even for Bertha she was overwhelmed by the pain and eventually 'lost' her own healing power. 


\section{Having this problem is very embarrassing}

A malignant fungating wound has a significant impact on psychological health and wellbeing. They had to learn to handle their chronic condition, which includes learning about the stigma of having a wound that was out of control. The category "Having this problem is very embarrassing" deals with the embarrassment the women felt because of symptoms like odour and excessive leakage from the wound and describes the consequences of this for their social life and identity. This category is subdivided in two subcategories "Being so unpredictable" and "Usual attractiveness disappeared".

\section{Being so unpredictable}

Embarrassment arising from the fungating nature or crater-shaped form of the wound and from the wound-related symptoms has a serious impact on daily life. According to Charmaz (1997) the embarrassment provoked by the illness as well as its visibility and the subsequent loss of control is a serious issue in daily life. Some participants (Irene, Helen, Linda and Livia) mentioned that it was very difficult to dress themselves because of the wound. As a result they had difficulty with daily activities. Others did not feel able to leave their home either because they were so busy managing the wound or because they feared someone might see, for example, blood on their clothes. All the women emphasised that living with a malignant fungating wound was a major challenge as the symptoms of the wound were unpredictable.

Some remarked how the presence of the wound affected their social behaviour, with them becoming isolated step by step from the outside world. This derives from the fact that on the one hand the symptoms were in general unpredictable and on the other the wound caused a sense of shame. All the women reported how their personality and identity had changed to and this affected their behaviour. Moreover, Helen describes how she is not the person she was:

"Yes, sometimes when I went shopping it was partially wet, so other people could see

it. Yes, so I went to the toilet and put absorbent dressings on it. I also changed my 
blouse. I always carried extra blouses in my bag. Sometimes I did not have enough blouses with me. Then I had to cover it with a scarf. You could not see it then. But I must say if you want to go out you very nearly have to bring the whole house with you. Having this problem is very embarrassing. You feel you are a completely different kind of person. Yes, I am not the person I used to be."

Helen's statement is very powerful and the changes in her life affected her identity She cannot leave the house without careful planning and bringing all sorts of materials and dressings with her. She needed access to a toilet so that she could change her dressings and always needed clothing to hide her problem. She felt shame that other people would see her wet clothing. Discussing illness within one's social environment can be a 'taboo' theme. Therefore access to support from friends and family members can sometimes be difficult.

Not only were the symptoms of the wound uncontrollable and unpredictable but also the speed of growth of the wound. Livia describes how the wound was not only eating away the breast but spreading further and further eroding and extending:

"It was growing so fast. First it ate away my breast and then it ate away further and further. Then it went round to my back. It is so embarrassing seeing it. It actually feels like l'm falling apart."

Livia's experience of the erosion and breakdown of the surface of her body leads to the falling apart of the self: 'I'm falling apart'. The cancer is uncontained and spreading further on the surface of the skin from the breast to the back. Lawton (1998) describes how as the cancer spreads it not only affects the boundedness of the body but also undermines one's sense of self and one's identity as a person. Livia's experience of her body is creating a loss of the self as she is 'falling apart'.

Linda also describes the relentless progression of the wound in her chest:

"Yes, because it has eaten into my chest so much, I have nothing there anymore. This is very stressful. You lose your femininity. I am afraid to go out of my apartment 
because everyone can see I have only one breast. So I try to wear loose clothes to hide it. And yes, I have to change the dressing a lot because it festers. Sometimes my clothes are wet. So I prefer to stay at home."

The cancer was eating away Linda's chest and she describes her loss of femininity, due to her changing body image. Her identity as a women and a sexual being was challenged and she felt marginalised from the society in which she lived. An intolerance of the disintegrating and decaying body is a feature of Western society, which demands the removal of such a body from view. Lawton (1998) describes how such bodies are often found in the hospicewhich provided a space of mediation between the bounded and unbounded body (Lawton 1998). For Linda she was fearful of going out with only one breast and a wound that leaks. She feels comfortable staying in her apartment where she is safe from the eyes of others.

To live with the embarrassment arising from the wound, some women evolved strategies so that they could tolerate the whole situation. One problem was changing the dressing as this caused serious physical and emotional distress. Every time they had to dress the wound, they were again confronted by their disease. Lisa reported her strategy for distracting herself:

"I hated changing the dressings. You were always reminded that you have cancer. Well you see the wound. It was so humiliating. To distract myself, I always watched a DVD when doing the dressing. That relieved my stress a bit. "

Lisa's statement demonstrates that visualisation techniques like watching a DVD can help as a coping strategy. She was watching TV-Series like Desperate Housewives to distract herself from the wound. The visibility of the cancer lead to a deep sorrow with regard to the whole situation and the existential meaning of the terminal nature of the disease. The visibility of the cancer was a constant reminder of their situation and took away any hope of recovery. 


\section{$\underline{\text { Usual attractiveness disappeared }}$}

Themes like sexuality, loss of attractiveness to those they loved and the taboo nature of the condition was discussed:

"And it is a question of the effect on sexuality, because the breast contributes significantly to it. Yes I often thought well do I appeal to men and can a man accept the wound? Yes I found it very special, when a man asked me, what do you have here. Yes I often thought about it, do I appeal to a man or not or does it bother him. It could be the case that my usual attractiveness to men had disappeared."

Anna was very concerned about her partner's acceptance of the wound. Body image is a key aspect of sexuality and covers feelings as well as attitudes towards the body (Tierney, 2008) and as Anna describes how the breast is significant in the physical and sexual relationship and is key aspect of attractiveness and sexual desire. Women report how their loved ones and partners did all they could to avoid having to touch the affected breast and their unbounded body. Irene reported:

"This was simply a taboo zone for him. He did not talk about it or touch it."

All women who were sexually active reported a loss of intimacy. All age groups brought up the topic of sexuality. Irene's statement is underlined by that of Linda who experienced similar feelings:

"Well he has simply ignored it. He did everything he could not to touch it."

There was a tendency for partners to avoid touching the breast or speaking about the wound as it was a taboo area for many partners. These statements by Irene and Linda showed that having a malignant fungating wound on the breast had significant effects on the quality of the relationship. The partners may have been fearful of hurting them if they touched the wound, and perhaps by discussing or touching the wound they were realising their loved one had a life threatening illness. Anna on the other hand dealt with her situation very pragmatically. 
She considered her relationship from a different angle. To reach this point of view she had to undergo a personal process:

"Yes and I thought, well then he has a choice, he can see it or even touch it or not. I do not care. I do not hide anything or do anything merely to please a man. I think we didn't get together just for sex but also for other reasons. So he has simply to deal with the situation, if he does not that is up to him. This has been an important process for me, reaching acceptance above all that I do not do his thinking for him. Is it too much for him at present or will it be a burden for him? No, I simply said no, he has to deal with this situation by himself."

Women who underwent a personal process, like that reported by Anna, showed that they not only had the relationship with their partner under control but their life as well in that Anna reached acceptance of the situation. Anna was self-employed and had to make all her own decisions. Having the situation under control means that she could keep working because she figured out how to manage her wound related symptoms and her relationship by insisting that her partner accepts her for who she is and to deal with the situation by himself. In this situation Anna describes her ability to manage her relationship with her partner in relation to his ability to accept her for who she is. This approach helps Anna to preserve her identity and present herself as someone who is in control of her life.

\section{Discussion}

The aim of the study was to explore the meaning of living with a malignant breast wound. The findings illustrate that managing a malignant fungating wound was a difficult and complex task for the women. The difficulty was to manage wound-related symptoms like exudate and to take control of the odour. Every woman had her own strategy to manage the wound. It was found that the wound related symptoms were unpredictable and uncontrollable. One of the main factors the women reported was the difficulty of managing their symptoms like malodour, bleeding, pain and exudate and the clustering of these symptoms is common in malignant fungating wounds. Smell and odour was a perpetual 
problem for the women. According to Lawton (2000) smell created a boundary around the patient, repelling others away. Classen et al. (1994) argued that odours cannot be contained. Odour escapes easily and crosses boundaries (Classen, 1994). A consequence of not containing the odours is that women who suffered from odour stayed at home and felt isolated and marginalised from society. They could contain the odour within a more bounded space such as the home (Lawton, 2000). The women also reported having difficulties with festering. Here fluids normally contained within the body are emitted and leak to the outside creating another aspect of breaking the usual body boundaries. This leakage often happened in an uncontrolled way. Managing the wound at home and trying to bring the wound under control caused the women considerable work. This meant that the wound became the centre of their lives. They had to adjust and dispense with their activities of daily living to adjust to the needs of the wound. Most of the women reported not wanting to become a burden to others. In Charmaz's (1997) study she also describes how people were anxious not to become a burden. Therefore women in the present study tried to solve the problem of the wound by managing it themselves. The problem was that they were living in a body that could not be trusted as the wound-related symptoms were uncontrollable.

The impossibility of achieving control of the many problems with the wound meant that the women lost control of their bodies. Losing control also reinforced an existential aspect of their life with cancer. The loss of control by cancer patients has been reported in the literature as one of the highest concerns and may affect the willingness to adopt positive health behaviours (Enskar, et al.,1997; McCaffrey, 2006). Wicks and Mitchell (2010) found in their study with ten cancer patients that there was a loss of control throughout the cancer treatment process resulting in a sense of frustration and anger.

Furthermore the loss of the bodily boundaries and the deteriorating condition of the wound is a visible sign of the advancing disease leading to considerable psychological, social and spiritual suffering over and above deteriorating physical health. It is stated in the literature that complex symptoms need to be differentiated between clinical syndromes such as 
anxiety disorders and bleeding for example and the broader psychological dimensions of suffering such as existential concerns and hope (Kelly, et al., 2006). The literature demonstrates that the suffering experienced in chronic and terminal illness demands an understanding of what makes people the individuals they are (Copp, 1994; Daneault, et al., 2004). According to Frank (2001) chronic illness involves suffering and this suffering is usually impossible to reveal totally to strangers. Suffering and loss are what the women reveal in this study and the reality that they can never again achieve the life that they had before the physical erosion of their body. Frank (2001) argues that "the core of suffering is the sense that something is irreparably wrong with our lives" (p. 355). Suffering also stands for loss and loss is something that is absent (Frank, 2001). Frank's work is based on personal narratives of his experiences of surviving a heart attack and cancer. In the current study the women lost their wholeness and the confidence in their body and this loss caused them immense distress as they were stuggling to cope (Grocott, 2007, Piggin and Jones 2007),

\section{Conclusions and implications for practice}

The increasing number of patients with advanced cancer due to improvements in survival rates may mean that more patients will require care for malignant wounds. The experiences of the women in this study demonstrate that losing control over the body meant losing control over themselves and their lives. The way they knew themselves in the past - with a bounded body - became a distant memory as they progressed through the journey of the illness and unboundedness as their disease was advancing and the wound became more demanding of their time. The women could no longer claim identities based upon previous lives and activities. They became fearful and dependent and their life revolved around the wound. The unboundedness of the body was demonstrated through the symptom experiences which had no limits. Symptom work was both physical and psychological as well as time consuming with many implications for quality of life. The physical demands of the wound stretched the women's competence and they did the best they could with the wound related symptoms like odour, bleeding, festering and pain. Psychologically they experienced deep suffering due to 
the consequences of living a marginal life in an unbounded body and the feeling that no one could help them.

To access the women's experiences and narratives and to support them a broader holistic and empathic approach to wound care and holistic assessment in the community is required. Good psychosocial and physical support and assessment will help the women to experience a coherent balance between the body, mind and spirit for example complimentary therapies may be useful to help the women to cope with the stress of living this way. The women did not seem to have access to information and modern dressings that could cope with large amounts of exudate and odour. There is a lack of adequate support by health care professionals for women with this condition. There needs to be more knowledgeable health professionals who can share their knowledge with patients and carers in relation to techniques for managing the wound and containing odour and exudate. Active measures related to supportive care and pain management need further consideration. The women report a lack of information and attention from health care professionals. They experience a lack of empowerment to approach health professionals for help due to their embarrassment and shame of living with this condition. 


\section{References}

Alexander, S. J., 2010. An intense and unforgettable experience: the lived experience of malignant wounds from the perspectives of patients, caregivers and nurses. Int Wound J, 7(6), 456-465.

Autier, P., Boniol, M., Lavecchia, C., Vatten, L., Gavin, A., Hery, C., et al., 2010. Disparities in breast cancer mortality trends between 30 European countries: retrospective trend analysis of WHO mortality database. British Journal of Medicine, 341, c3620.

Boon, H., Brophy, J., \& Lee, J., 2000. The community care of a patient with a fungating wound. British Journal of Nursing, 9(6 Suppl), S35-38.

Bowler, P. G., Jones, S. A., Davies, B. J., \& Coyle, E., 1999. Infection control properties of some wound dressings. Journal of Wound Care, 8(10), 499-502.

Charmaz, K., 1997. Good days and bad days - The self in chronic illness and time. Rutgers University Press New Brunswick, New Jersey.

Classen, D. C., 1994. Information management in infectious diseases: survival of the fittest. Clinical Infectious Diseases, 19(5), 902-909.

Copp, G., 1994. Palliative care nursing education: a review of research findings. Journal of Advanced Nursing, 19(3), 552-557.

Daneault, S., Lussier, V., Mongeau, S., Paille, P., Hudon, E., Dion, D., et al., 2004. The nature of suffering and its relief in the terminally ill: a qualitative study. Journal of Palliative Care, 20(1), 7-11. 
Enskar, K., Carlsson, M., Golsater, M., \& Hamrin, E., 1997. Symptom distress and life situation in adolescents with cancer. Cancer Nursing, 20(1), 23-33.

Eurocare 4, 2010. Survival of cancer patients in Europe. Milano. Retrieved 16.11.2011, from http://www.eurocare.it/Eurocare4/tabid/62/Default.aspx

Ferlay, J., Autier, P., Boniol, M., Heanue, M., Colombet, M., \& Boyle, P., 2007. Estimates of the cancer incidence and mortality in Europe in 2006. Annals of Oncology, 18(3), 581-592.

Frank, A. W., 2001. Can we research suffering? Qualitaitve Health Research, 11(3), 353-362.

Grocott, P., 2000. The palliative management of fungating malignant wounds. Journal of Wound Care, 9(1), 4-9.

Grocott, P., 2007. Care of patients with fungating malignant wounds. Nursing Standard, 21(24), 5758, 60, 62 passim.

Grocott, P., \& Cowley, S., 2001. The palliative management of fungating malignant wounds-generalising from multiple-case study data using a system of reasoning. International Journal of Nursing Studies, 38(5), 533-545.

Ivetic, O., \& Lyne, P. A., 1990. Fungating and ulcerating malignant lesions: a review of the literature. Journal of Advanced Nursing, 15(1), 83-88.

Kelly, B., McClement, S., \& Chochinov, H. M., 2006. Measurement of psychological distress in palliative care. Palliative Medicine, 20(8), 779-789.

Lawton, J., 2000. The Dying Process. Routledge, London.

Lawton, J., 1998. Contemporary hospice care: the sequestration of the unbounded body and 'dirty dying'. Sociology of Health and Illness, 20(2),121-143.

Lo SF, Hayter M, Hu WY, Tai CY, Hsu MY, Li YF., 2011. Symptom burden and quality of life in patients with malignant fungating wounds. Journal of Advanced Nursing, in press.

Lo, S. F., Hu, W. Y., Hayter, M., Chang, S. C., Hsu, M. Y., \& Wu, L. Y., 2008. Experiences of living with a malignant fungating wound: a qualitative study. Journal of Clinical Nursing, 17(20), 26992708. 
Lund-Nielsen, B., Midtgaard, J., Rorth, M., Gottrup, F., \& Adamsen, L., 2011. An avalanche of ignoring-a qualitative study of health care avoidance in women with malignant breast cancer wounds. Cancer Nursing, 34(4), 277-285.

Maida, V., Ennis, M., Kuziemsky, C., \& Trozzolo, L., 2009. Symptoms associated with malignant wounds: a prospective case series. Journal of Pain and Symptom Management, 37(2), 206211.

McCaffrey, C. N., 2006. Major stressors and their effects on the well-being of children with cancer. Journal of Pediatric Nursing, 21(1), 59-66.

Moffat, C., 2001. Non-healing leg ulceration. Nursing Times, 97(35), 49-50.

Mortimer, P., 2003. Management of skin problems: medical aspects. In D. Doyle, G. Hanks, N. Cherny \& K. Calman (Eds.), Oxford Textbook of palliative medicine (Vol. 3rd Edition). Oxford University Press, Oxford, pp.

Piggin, C., \& Jones, V., 2007. Malignant fungating wounds: an analysis of the lived experience. Int J Palliat Nurs, 13(8), 384-391.

Probst, S., 2010. Evidence-based managment of fungating wounds. Palliative Wound Care Supplement, Wounds UK, Aberdeen, 7-11.

Probst, S., Arber, A., \& Faithfull, S., 2009. Malignant fungating wounds: a survey of nurses' clinical practice in Switzerland. European Journal of Oncology Nursing, 13(4), 295-298.

Schmid-Buchi, S., Dassen, T., \& Halfens, R. J., 2005. [Experiencing the disease of breast cancer and getting life under control again]. Pflege, 18(6), 345-352.

Schulz, V., Triska, O.H. \& Tonkin, A., 2002. Malignant wounds caregiver-determined clinical problems. Journal of Pain Symptom Management, 24(6), 572-577.

Singletary, S. E., \& Cristofanilli, M., 2008. Defining the clinical diagnosis of inflammatory breast cancer. Semin Oncol, 35(1), 7-10.

Smith, J. A., Flowers, P., \& Larkin, M., 2009. Interpretative Phenomonological Analysis: Theory, Method and Research. SAGE, London 
Swiss-Association-of-Cancer-Registries, 2011. Statistics of Cancer Incidence 1983 - 2007. Retrieved 28.07.2011, from Swiss Association of Cancer Registries: http://asrt.ch/nicer/stat/i5ch8307.pdf

Thomas, S., 1992. Current Practices in the Management of Fungating Lesions and Radiotherapy Damaged Skin. The Surgical Materials Testing Laboratory, Bridgend.

Tierney, D. K., 2008. Sexuality: a quality-of-life issue for cancer survivors. Seminars in Oncology Nursing, 24(2), 71-79.

van Manen, M., 1990. Researching Lived Experiences, Human Science for an Action Sensitive Pedagogy. State University of New York Press, London, Ontario, Canada.

Wicks, L. \& A. Mitchell., 2010. The adolescent cancer experience: loss of control and benefit finding. European Journal of Cancer Care, 19(6),778-785.

Wilkes, L.M., Boxer, E. \& White, K., 2003. The hidden side of nursing: why caring for patients with malignant malodorous wounds is so difficult. Journal of Wound Care, 12, 76-80.

Young, C. V., 2005. The effects of malodorous fungating malignant wounds on body image and quality of life. Journal of Wound Care, 14(8), 359-362. 